\title{
ARTíCULOS
}

\section{LA CONFIGURACIÓN DE UN NACIONALISMO GALLEGO CONSERVADURISTA EN LA SEGUNDA REPÚBLICA: DEREITA GALEGUISTA}

\author{
The configuration of Galician "conservadurista" nationalism in \\ the Second Republic: Dereita Galeguista
}

Javier I. Senín Álvarez

Universidad de Santiago de Compostela (USC)

javiersenin@hotmail.com

\section{Cómo citar este artículo/Citation:}

Javier I. SENÍN ÁLVAREZ (2018), "La configuración de un nacionalismo gallego conservadurista en la Segunda República: Dereita Galeguista", Hispania Nova, 16, págs. 41 a 68, DOI: https://doi.org//0.20318/hn.2018.4031
Copyright: (c) HISPANIA NOVA es una revista debidamente registrada, con ISSN I I38-7319 y Depósito Legal M 9472-1998. Los textos publicados en esta revista están -si no se indica lo contrario- bajo una licencia Reconocimiento-Sin obras derivadas 3.0 España de Creative Commons. Puede copiarlos, distribuirlos y comunicarlos públicamente siempre que cite su autor y la revista y la institución que los publica y no haga con ellos obras derivadas. La licencia completa se puede consultar en: http://creativecommons.org/licenses/by-nd/3.0/es/deed.es

\begin{abstract}
Resumen: El Partido Galeguista constituyó la formación política más relevante de todas las surgidas a raíz de las nuevas posibilidades brindadas al nacionalismo gallego por parte de la Segunda República. A pesar de aglutinar en su seno a nacionalistas gallegos de derechas e izquierdas, el PG supo intervenir en la arena política gallega y española de un modo unitario y sin grandes tensiones internas, siendo el contexto político estatal el que terminó por inclinar al partido hacia la izquierda española para frenar a las derechas del país. Este estudio analiza las divergencias surgidas entre los sectores izquierdistas y conservadores del PG, las causas que condujeron a los segundos a escindirse (primero en Pontevedra y después en Ourense y Santiago) y las derivaciones de las sucesivas rupturas, materializadas en la creación de Dereita Galeguista.
\end{abstract}

Palabras clave: nacionalismo, Galicia, conservadurismo, religión, Dereita Galeguista, Segunda
República.. 
Abstract: The Partido Galeguista constituted the most relevant political formation of all those arisen as a result of the new possibilities offered to the Galician nationalism by the Second Republic. In spite of bringing together right-wing and left-wing Galician nationalists, the PG was able to intervene in the Galician and Spanish political arena in a unitary way and without major internal tensions, with the state political context ending up by inclining the party towards Left Spanish to curb the country's rights. This study analyzes the divergences between the leftist and conservative sectors of the PG, the causes that led the latter to split (first in Pontevedra and later in Ourense and Santiago) and the derivations of successive ruptures, materialized in the creation of Dereita Galeguista.

KeyWords: nationalism, Galicia, conservatism, religion, Dereita Galeguista, Second Republic. 


\section{Introducción}

El final de la dictadura de Primo de Rivera, la descomposición de la monarquía y la instauración de la Segunda República otorgaron a los nacionalismos periféricos grandes esperanzas de cara a la consecución de sus pretensiones políticas. En Galicia, así como en Cataluña y en el País Vasco, pronto se inició un proceso estatutario para conseguir la mayor autonomía posible dentro del Estado español. En este contexto tuvo lugar el nacimiento del Partido Galeguista, una formación política que aunaba diferentes grupos y personalidades cuya última finalidad era el reconocimiento jurídico de la personalidad de Galicia.

Sin embargo, no tardarían en surgir diferencias y tensiones entre los miembros del partido, generando diversas facciones dentro del mismo $y$, finalmente, su fragmentación. La posible alianza del PG con las izquierdas de ámbito nacional, junto con otras cuestiones igualmente tóxicas para la unidad de la formación política tales como la religión, darían lugar a la creación primero de la Dereita Galeguista de Pontevedra y, posteriormente, de las de Ourense y Santiago. Finalmente, ambas se fundirían en una única Dereita Galeguista, entendida como un grupo político activo en la lucha por la afirmación nacional de Galicia pero de signo tradicional y conservador.

Dereita Galeguista tuvo miembros destacados del galleguismo del momento, entre los que cabe mencionar al menos a Filgueira Valverde y Vicente Risco, y pese a su corta vida tuvo una actitud muy activa en las cuestiones políticas más relevantes del momento. Así, si bien las grandes divergencias con el sector más izquierdista del Partido Galeguista no habían permitido la permanencia en el mismo de buena parte de su facción conservadora, la nueva Dereita Galeguista trató de aunar igualmente los esfuerzos de todos los grupos políticos nacionalistas de Galicia en pos de un buen resultado en el proceso autonómico. 
A pesar de que el Partido Galeguista surgió a raíz de un problema que atañía a todos los gallegos y pretendió solucionarlo mediante la unión de todos ellos, resulta verdaderamente difícil imaginar un programa político satisfactorio para todos los sectores de la sociedad y posicionamientos ideológicos únicamente por ostentar la bandera de la soberanía nacional. Así lo planteaba Lois Manteiga a mediados de 1935:

«Eu non creo que baixo ningún conceito se poidan axuntar antagónicas tendenzas políticas. Cómo poden ir xuntos un comunista i-un cristián? eu non o sei, nin-o logro comprender. De ahí que todo ese preito de dereitas i-ezquerdas dentro do galeguismo ademáis de parecerme nefasto, antóxaseme algo así como un suterfuxio pra esconder a carenza de acción real. Eu sei que dada a cativeza numérica do Partido Galeguista, falar de divisións dentro del, arrepía un pouco. Pro é que hai que insistir na nulidade dun partido con esa mistura tan antagónica. Por qué non ha de haber galeguistas de dereitas e galeguistas de esquerdas, si estas verbas queren decir algo? Un programa político é unha reifa de cousas concretas. Un partido non se pode faguer baixo ese rubro só da autonomía; ésta ha se querer pra algo» ${ }^{1}$.

Este estudio parte, pues, de la curiosidad suscitada por una formación simplemente galleguista y, al menos en un principio, desideologizada. Un partido político de estas características, y más aún en el crispado contexto en el que se ubica, está llamado al enfrentamiento interno. El principal objetivo de esta investigación es estudiar las tensiones producidas dentro del PG, las cuales dieron lugar a la escisión primero de la Dereita Galeguista de Pontevedra y después de las de Ourense y Santiago, y analizar la historia de estas formaciones y de Dereita Galeguista, la cual no es sino el resultado de la unión de aquéllas. De este modo, se tratará de llevar a cabo un estudio monográfico de la DG atendiendo, especialmente, a las siguientes cuestiones: ¿Cómo han convivido la derecha y la izquierda galleguistas dentro del PG? ¿Qué motivaciones se han impuesto en las sucesivas escisiones llevadas a cabo por el sector conservador del partido? ¿Cuáles han sido las consecuencias de dichas escisiones? ¿Qué planteamientos ideológicos ostentó Dereita Galeguista? ¿Cómo transcurrió su corta vida en la arena política del momento y en el seno de la propia sociedad gallega de la Segunda República?

Para contestar a todas estas cuestiones es preciso realizar un exhaustivo análisis de las fuentes que se encuentran a nuestra disposición, y de entre ellas las

\footnotetext{
${ }^{1}$ Lois MANTEIGA, “Da nosa propia contemprazón. II”, Alento, 10-11-12 (1935), pág. 211.
} 
más aprovechables son, sin duda, las publicaciones periódicas de ámbito gallego. $A$ Nosa Terra, periódico primero de las Irmandades da Fala y después del Partido Galleguista, constituye una herramienta imprescindible para seguir la historia de este partido y de todos los sucesos acaecidos en la Galicia republicana, siendo nuestra fuente de referencia principal. No obstante, El Pueblo Gallego o el Heraldo de Galicia son también indispensables para seguir la pista de las Dereitas Galeguistas, publicándose, de hecho, algunos documentos de importancia pertenecientes a estas formaciones en dichos órganos. En menor medida, aunque con cierto protagonismo, serán consultados El Compostelano o los artículos políticos de Alento, mientras que otras publicaciones de la talla del Faro de Vigo o La Voz de Galicia serán útiles sólo de forma ocasional.

\section{Estado de la cuestión}

Dereita Galeguista ha sido siempre una formación política relativamente conocida debido a la enorme popularidad de algunos de sus grandes representantes, como Filgueira Valverde o Vicente Risco. No obstante, y a pesar de que estas y otras figuras del galleguismo hayan sido objeto de grandes estudios a lo largo de las últimas décadas, nunca se ha llevado a cabo un análisis profundo de Dereita Galeguista con una monografía minuciosa y concreta como resultado.

Ahora bien, esta afirmación debe ser matizada, pues han sido varios los historiadores que han dedicado a este grupo político una parte de trabajos más amplios sobre la historia del galleguismo. Así, cuando en 1985 Xavier Castro publicó $O$ galeguismo na encrucillada republicana dedicó un capítulo de su segundo volumen al estudio de la creación de las diversas Dereitas Galeguistas, así como sus programas, su unificación en un solo partido político e incluso al análisis de la sociología de sus miembros y del papel jugado por los mismos en el proceso estatutario de Galicia². Del mismo modo Justo Beramendi, en su De provincia a nación. Historia do galeguismo político (2007), que no es sino el resultado de diversas décadas de fructíferas investigaciones sobre el galleguismo, dedica un apartado a la Dereita Galeguista que,

\footnotetext{
${ }^{2}$ Xavier CASTRO PÉREZ, O galeguismo na encrucillada republicana (vol. 2), Ourense, Diputación Provincial, 1985.
} 
a pesar de limitarse a un puñado de páginas, resulta muy completo al enmarcarse dentro de una obra muy minuciosa que recorre toda la historia del galleguismo desde la época del provincialismo hasta la época de la Galicia autonómica y se detiene a analizar múltiples aspectos del mismo ${ }^{3}$.

Más abundantes son las obras que incorporan estudios sobre el Partido Galeguista y que, por ende, hacen referencia (e incluso, en ocasiones, ofrecen datos de gran relevancia) a la Dereita Galeguista. Tal es el caso de Los partidos políticos y la autonomía de Galicia, 1931-1936 (1976), en la que Alfonso Bozzo lleva a cabo un retrato muy ilustrativo de la arena política de la Segunda República con la cuestión autonómica de fondo y destaca, en su vinculación con la Dereita Galeguista, los intentos de la misma por neutralizar la ideologización del proceso ${ }^{4}$. Sin embargo, será Beramendi el encargado de ofrecer los estudios más relevantes sobre el Partido Galeguista y su relación con la historia del galleguismo, ofreciendo investigaciones verdaderamente interesantes sobre la identidad nacional y su historia en sus intervenciones en Los nacionalismos en la España de la II República (1991), Los 98 Ibéricos y el Mar (1998) o La España de los nacionalismos y las autonomías $(2001)^{5}$.

El mismo autor elaboró en 1981 un gran trabajo acerca de Vicente Risco y el nacionalismo gallego que resulta muy útil para la comprensión de la escisión acaecida en el seno del Partido Galeguista y los problemas formados en torno al tema del Estatuto, todo ello en un amplio marco de la historia del nacionalismo gallego ${ }^{6}$. Otras obras han recogido, antes y después y a lo largo de las décadas, datos de utilidad sobre el programa nacionalista, la ideología y la historia política de Risco, como

\footnotetext{
${ }^{3}$ Justo BERAMENDI, De provincia a nación. Historia do galeguismo político, Vigo, Xerais, 2007.

${ }^{4}$ Alfonso ALFONSO BOZZO, Los partidos políticos y la autonomía de Galicia. 1931-1936, Madrid, Akal, 1976.

${ }^{5}$ Véanse Justo BERAMENDI, "EI Partido Galleguista y poco más. Organización e ideologías del nacionalismo gallego en la II República", en Justo BERAMENDI y Bernardo MÁlZ, (eds.): Los nacionalismos en la España de la II República, 1991; ÍD., "Identidad nacional e identidad regional en España entre la Guerra del Francés y la Guerra Civil", en Los 98 Ibéricos y el Mar, III: El Estado y la Política, Madrid-Lisboa, Sociedad Estatal Lisboa '98, 1998, pp. 187-215; e ÍD., "La dinámica truncada del Partido Galeguista", en José Luis de la GRANJA, Justo BERAMENDI y Pere ANGUERA, La España de los nacionalismos y las autonomías, Madrid, Síntesis, 2001, pp. 154-164.

${ }^{6}$ Justo BERAMENDI, Vicente Risco no nacionalismo galego (2 vols.), Santiago de Compostela, Edicións do Cerne, 1981.
} 
ejemplifican los libros Vicente Risco na cultura galega (1963), de Ramón Lugrís ${ }^{7}$; Vicente Risco (1981), de Carlos Casares ${ }^{8}$; Nacionalismo gallego. La ideología de Vicente Risco (1981), de Francisco Bobillo9; u O nacionalismo kármico de Vicente Risco (2000), de Joaquim Ventura ${ }^{10}$. Figueira Valverde también ha sido objeto de análisis en diversas ocasiones, incluyéndose un artículo sobre él escrito por García Alén en la Gran Enciclopedia Gallega de $1974^{11}$ y siendo homenajeado por instituciones de gran prestigio cultural, como en Xosé Filgueira Valverde. 1906-1996. Un século en Galicia, en la cual se describe la personalidad de Filgueira, sus ideales religiosos y su participación en el Partido Galeguista y Dereita Galeguista ${ }^{12}$.

\section{El Partido Galeguista, una formación política para todos los gallegos}

El republicanismo español y el nacionalismo gallego explosionaron en la arena política de modo paralelo; sin embargo, el galleguismo todavía no se había armado lo suficiente para el advenimiento de la República, permaneciendo disperso en pequeños grupos políticos de poca trascendencia. Cuando aquella llegó no se hicieron esperar las declaraciones federalistas ${ }^{13} \mathrm{y}$, en general, la esperanza de poder habitar una Galicia autónoma y libre ${ }^{14}$.

\footnotetext{
${ }^{7}$ Ramón LUGRÍS, Vicente Risco na cultura galega; Vigo, Galaxia, 1963.

${ }^{8}$ Carlos CASARES, Vicente Risco, Vigo, Galaxia, 1981.

${ }^{9}$ Francisco BOBILLO, Nacionalismo gallego. La ideología de Vicente Risco, Madrid, Akal, 1981.

10 Joaquim VENTURA, O nacionalismo kármico de Vicente Risco, Santiago de Compostela, Laiovento, 2000.

${ }^{11}$ Alfredo GARCÍA ALÉN, "Filgueira Valverde, Xosé Fernando", en VV. AA., Gran Enciclopedia Gallega, tomo 13, Vitoria, Silverio Cañada, 1974.

12 Xosé Carlos VALLE PÉREZ, (ed.): Xosé Filgueira Valverde. 1906-1996. Un século en Galicia, Pontevedra, Museo de Pontevedra y Sociedad Estatal de Conmemoraciones Culturales, 2007.

${ }^{13}$ Amor, Risco, Otero Pedrayo y otros destacados galleguistas del momento hicieron público en mayo un escrito mostrando su actitud proclive a la creación de una República federal, al igual que el Partido Nacionalista Republicano y las Irmandades da Fala. "O nacionalismo galego e o momento autual. Declaración de fe republicana dos nazonalistas galegos", A Nosa Terra, 283 (1931), pp. 2-3.

${ }^{14}$ La visión habitual del contexto es apreciable a través del ejemplo de Víctor Casas, quien interpretó que «desapareceron xa os grandes oustáculos que se oponían á liberación da nos aterra. A monarquía e o caciquismo». Víctor CASAS, "Do momento", Ídem, pág. 5.
} 
Para cumplir los sueños del galleguismo era fundamental, no obstante, utilizar como herramienta política un gran partido de ese signo, como ya lo habían expresado en febrero de 1931 los nacionalistas galaico-porteños en una A Nosa Terra todavía vinculada a las Irmandades da Fala:

«La solución en que estriba todo el porvenir político de Galicia, sólo puede hallarse en la creación de un partido político gallego, republicano y galleguista. En lo espiritual y cultural nadie puede negar que se va de la periferia al centro. En lo político, en cambio aún se actúa del centro a la periferia. Dentro de poco tiempo -ahora ya- resultará ridículo que un republicano de Cataluña industrial, de Andalucía latifundista y del minifundio gallego, hablen en el parlamento un mismo lenguaje principista e ideológico, de igual origen exótico. Se va, indiscutiblemente, a que cada tendencia política posea su respectivo acento regional o nacional. Cataluña y Vasconia dieron ya su paso en este sentido. Galicia, no. Y Galicia debe darlo cuanto antes creando su propio partido, terminando de una vez con esas hijuelas sin savia de los partidos tradicionales españoles, así de la derecha como de la izquierda» ${ }^{15}$.

Unos meses después, en junio, Vicente Risco declaraba en la misma publicación periódica que

"A maioría dos galegos de todol-os partidos queren hoxe a autonomía. Compre, pol-o tanto convencelos de duas cousas:

Primeira: que o problema da autonomía debe ser anteposto niste instante a todo outro. Porque non facelo, porá en perigo o conquerimento da autonomía. Non debemos consentir qu'isto seña posposto. A anteposizón d'outros problemas, por parte do Goberno ou por parte dos partidos, poden non ser mais que armas e pretestos para soslayar a custión, fuxir d'ela ou desbotala.

Segunda: que dianted'iste problema, todo intrés ou difrenza partidista debe desaparecer, pol-o momento; qu'agora convén diante de nada, a unión de todol-os galegos para esta finalidade común. $O$ arredarse do frente úñeco autonomista pode constituir unha treición contra Galiza, de consecuencias irreparábeles para o noso pobo» ${ }^{16}$.

Finalmente, en diciembre alguien señalaba en el órgano de las Irmandades da Fala que

\footnotetext{
15 “Ao decorrel-os días”, A Nosa Terra, 280 (1931), pág. 2.

${ }^{16}$ Vicente RISCO, “Cumprindo co noso deber", A Nosa Terra, 284 (1931), pág. 3.
} 
«Todol-os partidos republicanos levaban a federación nos seus programas, cousa que logo se esqueceron de levar a practica, influidos tal vez pol-o ambiente e os intereses de Madrid. Con federación non haberia seguramente privilexios para ninguna rexión, pois os Estatutos non van a ser iguales. Esto é contrario democracia porque Galicia ten mais dereito á autonomía que Cataluña, a sua libertade convenlle mais a España, xa que somentes Galicia pode facer o casamento dos pobos hispanos. Non quere privilexios para Galicia, senon igualdade dentro do réxime federal.

Pero Galicia non vai renunciar os seus dereitos. Hai que formular un partido republicano autonomista, con programa de absoluta claridade e diputados comprometidos e defendel-a autonomía; un partido basado sobre principios xurídicos de liberdade económica e social. Este partido ten que ser republicano porque Galicia ten unha tradición anti-monárquica» ${ }^{17}$.

La creación del Partido Galeguista correspondía, pues, a una necesidad del pueblo gallego por encima de sus clases sociales y posiciones ideológicas; se trataba, al fin y al cabo, de un gran frente que defendiese los intereses gallegos en un momento de relativa abertura al autonomismo por parte del Estado. Con el telón de fondo de un Estatuto «que non ten os inconvenientes esquerdistas de Cataluña nin os dereitistas de Vasconia» ${ }^{18}$, los días cinco y seis de diciembre de 1931 se celebró en Pontevedra la VII Asamblea del Nacionalismo Gallego, en la cual quedó configurada la unión del galleguismo bajo una única dirección ${ }^{19}$. El día siete se terminó el programa fundacional del Partido Galeguista, que sería publicado en el número de enero de 1932 de A Nosa Terra.

Sus principios ideológicos encontraban sus influencias en la I Samblea Nacionalista, celebrada en Lugo en noviembre de 1918 y cuyos resultados se habían publicado no casualmente en el número de marzo de la misma publicación ${ }^{20}$. Galicia era caracterizada como una entidad con personalidad propia, republicana y con derecho a la autodeterminación, además de anti-imperialista, pacifista y proclive al federalismo internacional. Su organización, bastante descentralizada, debía estar en manos de sus ciudadanos, apostando por una fórmula con elementos de democracia

\footnotetext{
17 “O porvir dos partidos republicanos en Galicia”, A Nosa Terra, 290 (1931), pág. 5.

${ }^{18}$ Amaro de VILAMELLE, "Faiscas", A Nosa Terra, 287 (1931), pág. 7.

19 “Ao recorrel-os días”, A Nosa Terra, 291 (1932), pág. 1.

${ }^{20}$ Véase "O noso programa”, A Nosa Terra, 281 (1931), pp. 4-5.
} 
directa, aun existiendo una elección proporcional en la Cámara, y por la igualdad de derechos políticos para el sexo femenino.

En el ámbito laboral se aseguraba la aplicación de las normas internacionales y el reconocimiento de derechos sindicales, mientras que en el agro se instaba a mejorar la organización y sindicación, la repoblación forestal, la educación rural y la liberación de cargas para los trabajadores de la tierra, que sería considerada como herramienta de trabajo. En el mar, por su parte, el partido pretendía el retorno a los principios colectivistas pesqueros, la desgravación de sus productos, su protección y la modernización de los puertos.

En cuanto al régimen fiscal urgía desvincularse del Estado y suprimir diversos impuestos, a la vez que establecer uno progresivo sobre la renta. En materia de cultura Galicia ejercería soberanía plena sobre su patrimonio y el idioma gallego sería establecido en la enseñanza, pero ostentaría cooficialidad junto con el castellano en Galicia. Finalmente, las cuestiones judiciales más destacadas serían el reconocimiento de las modalidades del derecho civil gallego, la igualdad de derechos civiles de la mujer en caso de la emigración del marido y la amplitud del derecho de expropiación de cara a la socialización de empresas, riquezas naturales y municipalización de servicios públicos ${ }^{21}$.

Con un programa de corte bastante progresista y A Nosa Terra como órgano de expresión ${ }^{22}$, el Partido Galeguista daba sus primeros pasos en el seno de la República. Desde el primer momento manifestó su disposición e interés a colaborar en pos del Estatuto $^{23}$, que se convertiría en el principal objetivo de su existencia, y efectivamente se hizo con un cómodo lugar en la larga lucha por su creación. Así lo contaba el propio partido a mediados de 1933:

«O Partido fixo unha campaña estatutista intensa e afervoada e levóu despóis ao Parlamento do Estado a protesta enérxica de Galicia ante o trato, desconsiderado, desigual e inxusto, dun Goberno central, que, pra môr indiñación,

\footnotetext{
21 "Programa do Partido Galeguista”, A Nosa Terra, 291 (1932), pp. 4-5.

${ }^{22}$ En febrero esta publicación advertía a sus lectores de que «por acordo do Partido Galeguista "A NOSA TERRA" será dende agora órgao oficial do Partido». "Aos leitores", A Nosa Terra, 292 (1932), pág. 1.
}

23 “A posición do partido diante do Estatuto", A Nosa Terra, 294 (1932), pág. 1. 
se chamaba autonomista e puxera en atender âs peticións dos outros pobos a máis grande dilixencia.

O resultado desta laboura, que na môr parte das ocasións tivemos que facer compretamente soios, sen querer reparar na falla de asistenza dos que tiñan o mesmo compromiso que nós, foi a pubricación do decreto no que se autorizóu o plebiscito e por virtude do que se deu validez legal aos acordos da Asambreia de Compostela quedando recoñecida a personalidade do Comité nomeado por acordó dos Concellos galegos.

Galicia - por obra principal e casi escrusiva do Partido Galeguista- dispón xa de medios para conquerir axiña a facultade de se diñificar gobernándose de seu e ceibándose de camiño da môr parte dos danos e inxustizas de que é ouxeto. $O$ Partido cumpliu, pois, a súa misión e a primeira parte dos seus compromisos» ${ }^{24}$.

Las grandes personalidades del futuro PG habían acudido a la Asamblea proEstatuto reunida por iniciativa de la ORGA el 4 de junio de 1931, y la cual aunó las fuerzas de diversos ayuntamientos, diputaciones provinciales, partidos, sindicatos y otras instituciones gallegas con objeto de presentar hasta cuatro proyectos de Estatuto para Galicia. El siguiente gran paso en relación con el proceso autonómico lo daría el Ayuntamiento de Santiago en abril de 1932, al hacer un llamamiento a otras corporaciones gallegas para materializar el Estatuto, cuyo resultado sería la Asamblea del 3 de julio de ese año en el que diferentes partidos políticos, asociaciones y entidades políticas y culturales establecían la creación de una comisión encargada de redactar el texto estatutario que, finalmente, sería aprobado en la Asamblea de Ayuntamientos celebrada en Santiago los días 17, 18 y 19 de diciembre del mismo año ${ }^{25}$.

De forma paralela a esta incansable lucha por un Estatuto que no sería aprobado sino en la recta final de la Segunda República, la propia organización y estructura del Partido Galeguista fue creciendo y perfeccionándose a lo largo de los meses e incluso de los años. Mientras tanto, sus tres diputados (Castelao, Otero Pedrayo y Suárez Picayo) luchaban en las Cortes, los mítines, pasquines y conferencias se multiplicaban, los Grupos se vitalizaban o se creaban otros nuevos y

\footnotetext{
24 “A posición do Partido Galeguista diante do Estatuto”, A Nosa Terra, 298 (1933), pág. 3.

${ }^{25}$ Fernando SALGADO, “El Estatuto gallego del 36”, Tiempo de Historia, 22 (1976), pp. 25-28.
} 
una Federación de Mocedades Galeguistas ejercía como brazo joven de la formación política.

Pero el entusiasmo que había invadido los corazones de los galleguistas no tardaría en transformarse en decepción: el Tratado con Uruguay se traducía en una amenaza para la ganadería gallega ${ }^{26}$, el Partido Radical no tenía intención de llegar a un acuerdo en cuanto al Estatuto $^{27}$ y, para mayor preocupación, las derechas españolas amenazaban las posibilidades autonomistas del PG hasta el punto de que, una vez en el gobierno, echarían por tierra la materialización del Estatuto gallego.

Se ha visto cómo los conceptos de izquierda y derecha fueron sacrificados por los galleguistas republicanos en aras de aglutinar a todos los nacionalistas gallegos dentro de un mismo partido. Esa unión, aparentemente fuerte y sólidamente forjada en un principio, terminaría debilitándose tras diversos acontecimientos que harían necesaria una inclinación del partido hacia uno u otro lado, para romperse con las sucesivas escisiones llevadas a cabo por parte de algunos de sus miembros más conservadores.

La paz entre las facciones, nunca del todo unidas, se mantuvo durante los primeros años, y el propio partido se encargó en reiteradas ocasiones de recordar que en Galicia no existían derechas e izquierdas, sino galleguistas. En el día de Galicia de 1932 se instaba a la colaboración de todos los gallegos «sen mengua das difrenzas ideolóxicas, mais esquecendo persoalismos políticos e retesías locales» ${ }^{28}$, y la defensa que se hizo de un Otero Pedrayo «católico sinceiro, facendo uso da liberdade que aos afiliados concede n-iste punto o Partido» cuando El Ideal Gallego arremetió contra él, venía a demostrarlo ${ }^{29}$.

Aún así, en el mismo número que hacía esta declaración recibía la constitución de la Unión Socialista Gallega (USG) del modo siguiente: «dentro d-unha Galicia xa dona dos seus destiños e ceibe para se gobernar de seu, como conveña a todal-as

\footnotetext{
${ }^{26}$ A Nosa Terra, 304 (1933), pág. 1.

27 "O Partido Galeguista ao país galego", A Nosa Terra, 309 (1933), pág. 4.

28 "O Partido Galeguista a-o país no día de Galicia de 1932", A Nosa Terra, 295 (Núm. Extraordinario, 1932), p. 2.

29 “Coa república e contra a reaición do absolutismo centralista”, A Nosa Terra, 296 (1932), pág. 1.
} 
suas caraiterísticas, se teime despois de establecer normas socialistas, parécenos moi lexítimo», aunque también declaraba que «non eisiste na nosa Terra un partido desquerda galeguista típicamente marxista. ¿Causas d-elo? Non temos de nos pôr, niste intre, â sua precura» ${ }^{30}$.

En otras palabras, la ideologización de Galicia resultaba absurda, pero sólo mientras Galicia no estuviese constituida. Aunque esto ya lo había expresado Vicente Risco antes de la formación del partido, en realidad era una postura que contradecía el otro posicionamiento mediante el cual el PG justificaba la unión de sus ideológicamente inconexos miembros:

«A miudo, co pensamento posto na política española, se nos demanda se formamos un partido de dereitas ou de esquerdas. $E$ inda, sobre o texto mesmo do noso programa fanse as interpretacións máis dispares e arbitrarias.

Nós topamos $d$-abondo xustificada esta desourentación por parte de xentes que viven unha política allea e queren medir as nosas aspiracións con módulos estranos. Porque os partidos centralizados loitan a cotío por encher con tópicos o valeiro do seu contido e por subsituir con rubros a carencia de unha sinceira diferenciación doutriñal. E cando queren faguer o que chaman "política de realidades" refírense á política i-as realidades de outras terras, pero non da nosa.

Pol-a contra o Partido Galeguista posée unha tónica i-unha doutriña de seu. Unha tónica adquirida na longa tradición de loita pol-a unidade e pol-a libertade de Galicia, a compenetrar en unha acción común de homes arredrados pol-a sua concepción relixiosa ou social en outros terreos (...) O galeguismo camiña, pois, cara unha posición orixinalmente galega e negaríase a sí mesmo se valeirase $o$ contido do seu programa en moldes alleos» ${ }^{31}$.

De uno y otro modo, el partido no hacía sino intentar retrasar la inevitable ruptura, o convencerse a sí mismo y al pueblo gallego de que esta no tendría lugar porque Galicia no entendía de unas fórmulas -izquierdas y derechas- ajenas a ella y procedentes del exterior. Sin embargo, lo cierto era que existían descontentos en ambas facciones - porque, por supuesto, éstas eran una realidad-, y así el propio partido se lamentaba preocupado d que «ten sucedido que algúns elementos de

\footnotetext{
30 “¿Pol-o bo camiño?”, Ídem, pág. 4.

31 “Dereitas i esquerdas”, A Nosa Terra, 304 (1933), pág. 4.
} 
dereitas arredáronse do Partido pol-o programa, e bastantes elementos esquerdistas síntense defraudados pol-a táitica» ${ }^{32}$.

A finales de 1933 dejaría de ser preciso fingir que el galleguismo no entendía de ideologías, pues los nuevos «amos políticos de Galicia», aquellos aliados de la «traición», el «fraude» y el «centralismo», hacían necesaria a ojos del partido una alianza con cualquier elemento de izquierda que pudiese detener el avance de la derecha reaccionaria ${ }^{33}$.

Esta posibilidad fue estudiada seriamente en la III Asamblea anual del PG, cuyo acuerdo más destacado fue el de colaborar con las fuerzas de izquierda por obligación del propio momento. En realidad primó la concordia sobre la división, aceptando incluso Risco, que tuvo la posibilidad de expresar su opinión con respecto a la futura alianza, que si el momento obligaba a un acercamiento del partido a la izquierda éste debía ser llevado a cabo, siempre que esto no implicase un cambio en el programa del PG, en su táctica ni discriminación hacia los miembros que pensasen de un modo diferente en cuanto a cuestiones polémicas de la arena política española del momento. Lo importante, para Risco, era mantener la unidad del partido y, como también expresaría Álvarez Gallego, que no se fuese del mismo ningún afiliado ${ }^{34}$.

El sector derechista del partido se vio obligado, pues, a ceder ante las circunstancias, y aunque la unidad no se había roto sí se había abierto una honda brecha en el seno del PG. En realidad, la polémica que había existido siempre sobre las izquierdas y derechas que supuestamente no existían en Galicia quedaba resuelto a favor de las primeras, y así lo declaraba Carballo Calero poco después como si, de pronto, el galleguismo y la izquierda hubiesen caminado siempre de la mano a ojos de todos. Si antes el partido se empeñaba en hacer creer que izquierdas y derechas no significaban nada para el galleguismo, ahora eran sólo las derechas las que se desvinculaban del mismo:

\footnotetext{
32 "Dereitas i esquerdas", A Nosa Terra, 312 (1933), pág. 2.

33 “¿Unha nova posición?”, A Nosa Terra, 318 (1933), pág. 4.

34 "A III Asambreia anual do Partido Galeguista. Unha xornada histórica prâ Galeguidade e prâ Democracia Galega", A Nosa Terra, 321 (1934), pp. 1 y ss.
} 
«Os católicos de antre nós non poden sentirse identificados con tales xentes (la derecha). Cando agromóu unha esperanza, aínda que esvaída, en nós, das esquerdas partíu o aceso gorenteiro. É o preciso orientarse cara a ezquerda, porque da dereita nada pode agardar Galicia.

(...) Somos xa ezquerda, porque os galeguistas cristiáns sempre tiveron unha amplia visión dos problemas cuias solución programáticas definen o ezquerdismo. Saudemos respetuosamente á conciencia relixiosa.

(...) Dende o punto da ollada social, non hai dereitas no galeguismo» ${ }^{35}$.

\section{La primera escisión en el seno del PG: Dereita Galeguista de Pontevedra}

Tras dos años de intensa actividad política, reflejada en el progresivo aumento de los afiliados del Partido, el galleguismo se vio notoriamente afectado por los sucesos que estaban teniendo lugar en Madrid y que habían conducido a Castelao y a Bóveda al destierro y al órgano A Nosa Terra a varios meses de suspensión. Así pues, en un clima crispado por la amenaza de las derechas españolas - que, obviamente, ponía también en jaque el proceso autonómico-, la tensión entre el izquierdismo y un conservadurismo reducido a galleguismo cristiano sólo era un elemento más del que preocuparse, y no el más relevante. Sin embargo, en abril de 1935 se producirían los primeros roces de gravedad entre ambas facciones.

El PG había mantenido, hasta su alianza con las formaciones republicanas de izquierda del país, una actitud desideologizada aun ostentando un programa de signo progresista. Desde ese momento dejaron de existir las alas izquierda y derecha del partido, pues la derecha se asociaba al reaccionario gobierno de la República y los conservadores galleguistas sólo se diferenciaban de la izquierda del partido en sus creencias religiosas. Así, con ocasión de una crítica a un número de El Pueblo Gallego en el que presumiblemente se manipularon datos de una opinión particular de Raza Celta sobre la posibilidad de crear un nuevo partido de decantarse el PG por la izquierda, éste declaraba que

\footnotetext{
${ }^{35}$ Ricardo CARBALLLO CALERO, “Xa somos esquerda”, A Nosa Terra, 323 (1934), pág. 1.
} 
"Queda únicamente como liña divisoria o problema relixioso. Máis eso entre nós e sabido que non é. O Partido Galeguista remite esa custión inelegante e irrespeitosamente tratada por outros partidos, tanto de dereita que fán d-il un armacoma de esquerda que fán d-il un odio a intimidade das conciencias. O Partido Galeguista, liberal e moderno, praitica, os máisimo respeito pras relixións, a máisima tolerancia» ${ }^{36}$.

En realidad, el problema religioso y la preocupación por la cada vez más clara deriva izquierdista del partido caminaban unidos e inquietaban a buena parte del sector conservador del PG. En los meses que precedieron a la primera escisión es apreciable en los artículos de Risco (con toda seguridad el más interesado en la teoría galleguista de los futuros escindidos) una honda preocupación por una religión que él consideraba inherente al galleguismo ${ }^{37}$. Quizá el fragmento más representativo de ello sea el siguiente:

«A religión, que hai quen deixa de fora do cadro do galeguismo. E non pode ser. Nen pode ser galego inteiro quen non cree e confesa o que creeu e confesou decote, e cree e confesa aínda o pobo galego-non pode ter un conceito trascendente da Patria.

A estructura social tradicional, que tamén hai quen coida de posíbele transformación. E non debe ser. Pende do sangue da nosa raza ben antiga, e pende na fe religiosa que se fixo consustancial co-ela. Ir contra ela é ir contra do corpo e da y-alma de Galiza» ${ }^{38}$.

De hecho Risco había defendido en reiteradas ocasiones el papel restaurador del nacionalismo, el valor de la religión dentro de ese proceso, fundamental al menos en el caso gallego, e incluso había encontrado mayores semejanzas en el nacionalismo gallego con el fascismo (el cual pretende una concentración de fuerzas en contra de las luchas políticas, de clase o de intereses particulares, poniendo por encima de eso el bien común, y pretende que la organización y legislación de la nación se adapten al modo de ser de la misma) que con el comunismo (que a veces defiende los derechos nacionales, pero el cual es universalista contrario a la cohesión nacional).

\footnotetext{
36 "O Partido Galeguista, por enriba de dereitas i-esquerdas", A Nosa Terra, 354 (1935), pág. 1.

${ }^{37}$ De hecho, para Risco «iste movemento (el católico), e o das reivindicacións nacionás son os únicos que poden salvar o mundo», concluyendo que "cómpre chegar â síntese dos dous». Vicente RISCO, "Leria nova. O movemento católico", Heraldo de Galicia, pág. 1, 25/03/1935.

${ }^{38}$ Vicente RISCO, “Leria nova. Imos precisando mais”, Hidalgo de Galicia, pág. 1, 18/02/1935.
} 
Dando un paso más en su ideologización del nacionalismo, incluso se muestra receptivo a las ideas racistas, y es que si bien se niega a dar una respuesta rotunda («non diremos que sí nen que non, n-un asunto tan espiñento»), asegura que «o certo é que, na poboación galega, os elementos celta e germánico semellan predominantes, e dende logo máis abondosos que en ningunha outra tera da Península» ${ }^{39}$.

En medio del crispado ambiente por la cada vez más alarmante inclinación del Partido hacia la izquierda, a inicios de 1935 la riña entre Risco y Castelao se manifestaba ya con fuerza. La visión del orensano sobre la actitud del PG ante el momento ya la conocemos; la de Castelao ante las enérgicas protestas de Risco es descrita por aquél en una carta enviada a Otero Pedrayo en enero de 1935:

"Risco escribeume, n'efeito, unha longa carta i-eu contesteulle con outra máis longa ainda. Non sei se a remataría de ler. Riso, que é un santo, ten dúas chatas: a de doerse porque non lle fan caso e a de botarse de adiviño. El ten razón e os demáis tamén a teñen. A min paréceme que as preocupacións do Risco proveñen do medo que lle dá o trunfo. O Risco non é arriscado. Eu, en troques, teño fé cega no galeguismo, que chegará a ver o que a Galiza lle conveña. Risco quer metelo nos raíles do tren i-eu coido que debe ir por unha estrada ancha, unhas veces â esquerda e outras â dereita e sempre a bó paso. Eu presinto que a fuga esquerdista da maoría do galeguismo non ten consistencia para rexer a verdadeira realidade galega e que a tendencia dereitista tampouco remediará os nosos alifaces. Galiza é un país de centro, no social e no económico, e o galeguismo non poderá ser outra cousa. E no aspeuto moral ¿non é tamén de centro? O bandazo que dou car'a esquerda é debido a que unha terrible onda lle pegou no lado dereito e daría o bandazo car'a dereita se a onda viñese pol-a esquerda. ¿Pero é qué imos a ter sempre este temporal e non navegaremos algunha vez con estabilidade? Creo que o trunfo depende da nosa resistencia. $\mathrm{Na}$ carta que lle escribín a Risco dígolle, de seguro, moitas parvadas; pero creo que estou acertado no fondo» ${ }^{40}$.

Y fue, probablemente, Otero Pedrayo quien advirtió a Castelao de las tentativas de Risco de fragmentar el PG y arrastrar a su facción conservadora a un nuevo partido galleguista de derechas. Castelao, enterado de estos acontecimientos, arremetió contra Risco muy duramente en la carta que transcribimos íntegramente a continuación:

39 Vicente RISCO, "Nacionalismo galego. III. Os objetivos", Alento, 5 (1934), pp. 84-86; ÍD., "Nacionalismo galego. Formas modernas de nacionalismo", Alento, 7-8 (1935), pp. 157-163.

${ }^{40}$ Alfonso R. CASTELAO, "Carta a Ramón Otero Pedrayo. Badaxoz, 10 de xaneiro de 1935", en Obras, Vol. 6, Vigo, Galaxia, 2000, pp. 239-240. 
"Querido Vicente: Un galeguista dos máis vellos danosa Irmandade, que dou mostras certas e verdadeiras de amor á nosa Terra (Tanto ou máis que ti e min, dentro das suas forzas) quéixase, e a meu xuicio con sobrada razón e motivo, da tua nova manía de excomulgar do galeguismo a quen non pensé coma ti.

Certas afirmacións tuas non poden tomarse ó pe da letra porque xurde delas unha intención política que non se axeita ás normas que sempre, sempre foron orgunlo dos galeguistas.

Non quero entrar no fondo do asunto e déixoche en paz coa tua conciencia. Fai e desfai o que queiras.

Supoño que terás recibido unha carta miña, longa de máis. Estou arrepentido de intervir perto de ti, pois agora decátome de que a ti o que che gosta é esto que estás facendo, e querendo eu facer un ben cicáis fixese mal...

Desfai o Partido dunha vez. Déixate de Lerias e ponte ó frente de quen che siga. Lévate contigo o mellor que temos e esterilizalle as enerxías que teñen. Eu quédome onde esou e coa carraxe do mesmo demo do inferno - ceibe de vencellos- seguirei na política aitiva, con quen sexa capaz de dar a vida e a ialma por Galiza, a Galiza que seña, a que poidamos lograr. Apertas» ${ }^{41}$.

En este contexto tuvo lugar la IV Asamblea del PG, desarrollada los días 20 y 21 de abril de 1935 en Santiago. Risco no acudió a ella, pero la intervención de otros miembros del Partido con objeto de exponer su preocupación y plantear salidas viables a la tensión izquierda-derecha demuestra que eran muchos los conservadores que veían una traición al galleguismo en el rumbo que el PG estaba tomando. Quizá el discurso más curioso fuera el de Otero Pedrayo que, preocupado por el hecho de que la mayor parte de la asamblea tuviese un modo de pensar diferente al suyo, planteó la posibilidad de rechazar cualquier tipo de vínculo con organizaciones de carácter marxista, lo cual fue rechazado por la asamblea como él mismo preveía; tras mostrar su rechazo del marxismo -al que, sin embargo, respetaba enormemente-, así como del derechismo al uso español, señaló que, aunque su propuesta no prosperara, él permanecería en el partido, como realmente hizo incluso después de las diversas escisiones. Banet Fontenla, por su parte, pidió al partido que sus interacciones con otras fuerzas se encaminasen en actos públicos hacia cauces galleguistas, dado el giro

\footnotetext{
${ }^{41}$ Alfonso R. CASTELAO, "Carta a Vicente Risco. Sen lugar (Badaxoz), 1 de marzo de 1935", en Obras..., op. cit., pág. 245.
} 
hacia la izquierda que la formación nacionalista había tomado; Mosquera, finalmente, planteó directamente la posibilidad de formar una organización de derechas ${ }^{42}$.

Y aunque Otero Pedrayo, Banet, Mosquera o Risco permanecieron en el partido a pesar de su manifiesto descontento para con el mismo, Filgueira Valverde, que había permanecido mudo y expectante durante las tensiones retratadas anteriormente, fue quien capitaneó la primera escisión del ala conservadora de la formación, si bien la mayor parte de la derecha galleguista no le acompañó a su camino. Tres días después de haberse cerrado la IV Asamblea del PG -la cual, por cierto, ratificaba la alianza con la izquierda nacional-, José Filgueira Valverde envió una carta al secretario general del partido, Manuel Gómez Román, expresándole sus deseos de darse de baja en el mismo. La carta, escrita en un tono más profundo y melancólico que enfadado y superficial, muestra las razones de Filgueira Valverde de romper con un partido al que respeta tanto en cuanto defiende el galleguismo, pero al que ya no puede pertenecer por hallarse ahora vinculado a fuerzas externas - españolas- que lo dominan y, encima, opuestas al cristianismo y a la tradición que tanto defiende Filgueira Valverde ${ }^{43}$.

Así se explica la creación de Dereita Galeguista poco después. El 25 de mayo de 1935 Filgueira Valverde, José García Vidal, José Lino Sánchez, Darío Caramés, José Sesto López y José Martínez Tiscar firmaron un manifiesto en Pontevedra en el que esclarecían los puntos básicos del programa de la nueva Dereita Galeguista de Pontevedra y el cual fue publicado en diversos órganos de expresión de Galicia en las siguientes semanas. El naciente partido se declaraba galleguista y defensor de los particularismos de Galicia; por lo tanto, su idioma era visto como conductor de la cultura, exponente de la misma y factor de su creación, además de herramienta para mantener el alma de Galicia. La religión, que había sido uno de los grandes motivos que habían originado la escisión, era defendida en múltiples modos y formas y valorada de un modo individual y colectivo, incluso moral y político. Véase el apartado completo:

\footnotetext{
42 “A IV Asambreia do partido”, A Nosa Terra, 363 (1935), pág. 3.

${ }^{43}$ Esta carta, redactada por Filgueira Valverde el 23 de abril de 1935 en Pontevedra, ha sido consultada en Xavier CASTRO PÉREZ, O galeguismo..., op. cit., vol. 2, pág. 899.
} 
"O respeto a creencia relixiosa e á práctica do seu culto é postulado de liberdade individual de conciencia, é socialmente un elemento de intregación política. Consideramos a defensa dos valores espirituales do noso pobo vinculada á defensa do esprito Cristián que os informe. Sostemos o dereito a profesar, practicar, i-ensinar púbricamente a Relixión Católica. Como creentes e como galegos non soio nos oporemos a descristianización de Galicia, senón que intentaremos levar á vida intelectual e a vida lexislativa solucións cristiáns. Exaltando o valor da xerarquía ecresiásticas na vida do noso pobo, non dudariamos en destiñar fondos púbricos, cando a Constitución do Estado o permita, a mellorar as institucións formadoras do crero, para que poida de cheo cumprir a súa misión moralizadora i-evanxélica» ${ }^{44}$.

Por otro lado, apuesta por la democracia y arremete tanto contra el marxismo, incompatible con el galleguismo por aspirar a la «dexeneración das culturas nun internacionalismo con idioma único e cultura proletaria única», como contra el fascismo, cuyo Estado «absorbe o cibdadán e descoñece os seus dereitos». Económicamente se ubica dentro del cooperativismo, que describe como una «democracia de pequenos propietarios e de productores organizados cooperativamente que teñen de actividade económica un concepto subordinado ao senso moral dos fins humáns», y se muestra preocupado por los problemas económicos particulares de Galicia, puesto que la sociedad de la misma «descansa na organización rural e mariñeira». Finalmente, se declara autonomista, republicano y repetuoso para con los demás partidos gallegos, estrechando especialmente la mano del Partido Galeguista ${ }^{45}$.

Por otro lado, las reacciones ante la escisión de Dereita Galeguista no se hicieron esperar dentro del PG, y en diversas publicaciones tanto la nueva formación como sus miembros - $\mathrm{y}$ especialmente, Filgueira Valverde- fueron atacados duramente. Quizá el más destacado enemigo del nuevo partido fuera Castelao, quien reaccionó al enterarse del siguiente modo:

"Quero que seipan os firmantes do manifesto e todos cantos acudan á súa chamada, que eu, galeguista nato, opoñereime a calquera entendimento con eles,

\footnotetext{
44 “Dereita Galeguista de Pontevedra”, A Nosa Terra, 370 (1935), pág. 4.

${ }^{45}$ Ibídem.
} 
porque non creo na fortaleza dos seus sentimentos patriotísticos nin estou disposto a deixarme convencer con adoas de vidro» ${ }^{46}$.

Además decía de estos conservadores que «poñen a Galiza por debaixo de outos intreses, que nin transiquera son esprituales», y señalaba que "un galeguista verdadeiramente Cristián non ten porqué arredarse do noso parrido, nin para salvar a nosa Terra nin para salvar a súa alma» ${ }^{47}$. En definitiva, la pacífica ruptura que había planeado Filgueira sería, al menos con algunos de sus antiguos compañeros, difícil de llevar a cabo dadas las hostilidades que hacia la nueva formación existían en el seno del galleguismo. Por suerte para la derecha galleguista todavía había algunos miembros importantes del PG decididos a imponer la comprensión y la paz entre los gallegos, y así Bóveda (aunque movido, posiblemente, por los lazos familiares que le unían a algún miembro de Dereita Galeguista) arremetió contra los ataques lanzados sobre Filgueira y los suyos, los cuales, dice, «me dieron como cousa propia», y señaló que, a pesar de no compartir la postura mantenida por los conservadores escindidos, que debían haber actuado de forma similar a Otero Pedrayo, Filgueira Valverde había jugado un papel de relevancia en el seno del PG y merecía los respetos del galleguismo $^{48}$. Cabe decir, sin embargo, que el propio Bóveda había enviado dos semanas antes una carta a Filgueira Valverde acusándolo de llevar a cabo una acción poco respetable y justificada en acusaciones injustas ${ }^{49}$.

\section{Las nuevas escisiones y su unificación en Dereita Galeguista}

Más allá de las habituales tensiones existentes en el seno del partido, acentuadas en momentos clave para el futuro del mismo (tales como la IV Asamblea o las elecciones de febrero de 1936), las escisiones de Ourense y Santiago no fueron precedidas de sucesos traumáticos ni violentos. Sencillamente, la alianza frentepopulista terminó con la ya agotada paciencia de los galleguistas cristianos de

\footnotetext{
${ }^{46}$ Alfonso R. CASTELAO, "Verbas de chumbo. XI", A Nosa Terra, 372 (1935), pág. 1.

${ }^{47}$ Alfonso R. CASTELAO, "Verbas de chumbo. Xl", A Nosa Terra, 372 (1935), pág. 1.

${ }^{48}$ Alexandro BÓVEDA, “Filgueira Valverde e nós”, A Nosa Terra, 368 (1935), pág. 1.

${ }^{49}$ Esta carta fue escrita por Bóveda el 10 de mayo de 1935 en Cádiz. Ha sido consultada en Xavier CASTRO PÉREZ, O galeguismo..., op. cit., vol. 2, pág. 902.
} 
Ourense y, al marcharse éstos del partido, dejaron la puerta abierta para que los conservadores de Santiago siguiesen su ejemplo.

Las elecciones de febrero de 1936 fueron consideradas por el galleguismo como una puerta hacia la autonomía, pues la victoria del Frente Popular posibilitaría la realización del referéndum que desembocaría, al ser el pueblo proclive al Estatuto, en la creación de esa Galicia autónoma con la que tanto se había soñado en las páginas de A Nosa Terra y otros órganos de expresión vinculados al nacionalismo gallego.

En enero, Santiago de Compostela acogería la II Asamblea extraordinaria del Partido Galeguista, que éste celebraría con objeto de fijar su posición de cara a las elecciones. En realidad el PG no se encontraba en una situación muy cómoda en el seno del Frente Popular, pues éste había invitado a formar parte del mismo sólo a las circunscripciones de A Coruña y Pontevedra, dejando de lado las de Lugo y Ourense, y había ofrecido una representación poco atractiva al Partido (1, frente a los 15 de Izquierda Republicana en la proporcionalidad de fuerzas propuesta en los Comités Conjuntos del Frente). Sin embargo, en la II Asamblea se decidió estrechar la mano a la alianza de izquierdas para obtener un halo de esperanza autonomista ${ }^{50}$. Los acuerdos se resumen en la siguiente nota-manifiesto:

"A II Asambreia do P. G., que se xunta en horas de fonda e grave responsabilidade para cantos actuamos na politica galega, despóis de ergueita e meditada discusión adoptou os seguintes acordos:

Primeiro: Aprobar unánimemente a xestión que, velando celosamente pol-os dereitos e a dinidade do Partido e co pensamento posto en servir con lealtade a Galicia e á Repúbrica, ven realizando o noso Comité Executivo.

Segundo: Ratificar pubricamente a lealtade do Partido Galeguista aos compromisos de orde político que ten contraídos ante a loita electoral coas forzas afíns sin outra condición que a de recabar para o Partido, nas condicións que con aquelas se poideran formar, o trato, consideración e proporcionalidade de postos a que a súa laboura e organización o fán acreedor.

Terceiro. Facultar ao Comité Executivo, constituido en Direitorio eleitoral, para que, interpretando o unánime e craro sentir da Asambreia, e conforme ás

\footnotetext{
50 “A II Asambreia extraordinaria do Partido”, A Nosa Terra, 401 (1936), pp. 1-2.
} 
características especiaes que cada unha das circunscripcións galegas presenta, determiñe as normas asegún as que o Partido haberá de actuar n-elas»" ${ }^{51}$.

Esta alianza con el Frente Popular derivó en una nueva lucha entre las facciones izquierdista y conservadora. De nuevo, Otero Pedrayo tuvo un papel destacado en ella, y en una nueva ocasión la disciplina de partido le hizo permanecer en el PG sin sentirse parte del mismo. Así, Otero señaló que «co trunfo electoral medra outra invasión na Galicia, e dende logo contra Galicia», haciendo referencia al papel que el PG tenía en la arena política española como títere de los partidos nacionales, y definió el «ezquerdismo ibérico» como «un novo espellismo engaio lador» ${ }^{52}$. Pero Otero no tenía aspiraciones rupturistas; en Ourense y Santiago, sin embargo, sí las había.

El ocho de febrero de 1936 Risco presidió una reunión en Ourense en la que él mismo, José Fernández Borrajo, José Antonio Varela, Isidro Guede, José Luis Parente, Ángel Martínez Doval, José Perille Garra y José Goyanes acordaron firmar un manifiesto a través del cual crearían una nueva formación política galleguista y conservadora. El manifiesto, que saldría a la luz el diez de febrero en el Heraldo de Galicia, señalaba la intención del nuevo grupo de seguir la estela de Dereita Galeguista de Pontevedra, y justificaba su creación en el contexto de un galleguismo -el del PG- del que no participaban en absoluto y cuyos principios no compartían, lo cual conducía a la necesidad de formar un nuevo partido político independiente que conservase y defendiese los principios católicos y tradicionales de Galicia, además de su autonomía, sus intereses, su sociedad, su cultura, su economía, etc ${ }^{53}$.

No habían pasado dos meses cuando la misma publicación sostenía que podían haber surgido nuevas organizaciones de Dereita Galeguista en A Coruña, Vigo y Santiago de Compostela, aun sin poder asegurar la fiabilidad de sus fuentes ${ }^{54}$. El uno de abril se confirmaban al menos parte de estos rumores, al formarse en Santiago la Dereita Galeguista de esta ciudad, cuyo manifiesto fue firmado por Manuel Banet

\footnotetext{
51 "Nota-manifesto da Asambreia", A Nosa Terra, 401 (1936), pág. 3.

${ }^{52}$ Ramón OTERO PEDRAYO, “Tribuna libre. Desgaleguización”, A Nosa Terra, 408 (1936), pág. 1.

53 “Dereita Galeguista â opinión galega”, Heraldo de Galicia, pág. 1, 10/02/1936.

54 “La política gallega”, Heraldo de Galicia, pág. 1, 30/03/1936.
} 
Fontenla, Xosé Mosquera Pérez, Daniel Louzao, Carlos Seija Subirá, Manuel Jiménez Puente y Manuel Beiras García. Básicamente éstos exponían sus deseos de alejarse del partido en el que habían militado, acatando las decisiones que la mayoría había impuesto sin compartirlas, y sumarse a la oleada escisionista que las derechas del partido estaban llevando a cabo; de hecho, hacían propio los principios del manifiesto de Ourense, mostrando abiertamente la influencia que el lanzamiento de éste había ejercido en los santiagueses.

El número de nacionalistas gallegos adheridos a nuevas formaciones de Dereita Galeguista fue, pues, aumentando progresivamente desde aquella primera ruptura protagonizada por Filgueira Valverde y los suyos. Tras las nuevas escisiones, Filgueira, Risco y los demás elementos derechistas del galleguismo decidieron llevar a cabo una reunión, presidida por Risco y en la que, al fin, se ponía en funcionamiento la Dereita Galeguista, cuyas bases serían aprobadas ese mismo día y publicadas en el Heraldo de Galicia del día siguiente.

Galicia era considerada una nacionalidad con particularismos, los cuales justificaban sus derechos autonómicos dentro de un Estado español pluralista, si bien la fórmula autonómica no se declaraba definitiva. Además, se exigía el reconocimiento de la parroquia como entidad jurídica. En el gobierno gallego, además de los partidos políticos elegidos por el pueblo, debían participar «as corporaciós que representan intreses económicos e espirituaes», y además las costumbres debían ser tenidas en cuenta como fuente de derecho.

En lo que respecta al mundo de la cultura no encontramos novedades: conservación y desarrollo de la tradición, la educación, el gallego - que sería idioma cooficial junto con el castellano-, estímulos culturales, etc. La religión católica, por su parte, es considerada «como fundamental da tradición galega enxebre», abogando por un concordato con la Iglesia y defendiendo el derecho a profesar y propulsar la religión, así como a educar en la misma. En relación con esto, el problema obrero era derivado a las Encíclicas sociales de los «Romanos Pontífices».

La estructura social de «régime familiar tradicional» debía mantenerse, pero también era preciso desarrollar los lazos parroquiales, vecinales y el sentimiento de amenidad gallega. Finalmente, se afirmaba que Galicia, siendo una tierra 
esencialmente agraria, debía prestar atención especial al mundo rural y campesino, así como defender el régimen de la pequeña propiedad, el régimen familiar y una justa regulación de los contratos de cultivo. La táctica del partido para conseguir todos estos puntos rechazaría la violencia, la retórica, la sensiblería, la hipérbole y «o estilo e o tecnicismo da política hespañola» ${ }^{55}$.

\section{Conclusiones}

Dereita Galeguista es el resultado natural del proceso de formación de un nacionalismo más o menos maduro, en este caso el gallego, en la arena política de su geografía. En todo nacionalismo periférico existe tendencia a la proliferación de distintas tendencias ideológicas dado que, como ocurre en la nación-Estado, resulta dificultosa la tarea de impulsar un partido político de carácter nacionalista sin introducir en él elementos de izquierda o derecha. La democracia derivada del establecimiento de un régimen republicano en 1931 permitió al galleguismo experimentar un crecimiento en todos los sentidos desconocido hasta el momento, derivando tal crecimiento en la creación de partidos nacionalistas diferentes si bien, sin duda, el Partido Galeguista sería durante toda la II República el mayor referente del galleguismo. Si en un principio el objetivo era dar lugar a un partido político meramente galleguista, las tensiones entre las distintas ideologías existentes en el seno del galleguismo o partidos de ámbito nacional darían lugar a la creación de formaciones izquierdistas, como la Unión Socialista Gallega, o conservadoras, cuya primera experimentación tendría a Dereita Galeguista como protagonista.

No obstante, no existieron intentos de escisión dentro del Partido Galeguista por parte de sus sectores más conservadores sino tras la deriva izquierdista del mismo, resultando la creación de las distintas Dereitas Galeguistas más un mecanismo de defensa ante la "socialización" del galleguismo que una proclividad de sus miembros a diferenciación ideológica con respecto a un partido que, como se puede observar a través de la comparación de sus programas ideológicos, apenas difiere en sus bases

\footnotetext{
55 "Bases para o programa da federación das forzas nacionalistas e galeguistas de dereita, aprobadas na xuntanza do 19 de Abril de 1936 en Ourense”, Heraldo de Galicia, pág. 4, 20/04/1936.
} 
(salvo en lo tocante a la religión) de los conservadores. La distancia ideológica entre izquierdas y derechas dentro del PG nunca había supuesto un problema serio, siendo únicamente un pequeño obstáculo para la total homogenización del partido (como otras cuestiones que nunca llegaron a cobrar importancia como objeto de debate), algo que tampoco se creía necesario. EI PG resultaba de la unión de todos los galleguistas y, aunque esto suponía la existencia de pequeñas polémicas periódicas, no tenía por qué suponer más que pequeños roces.

La problemática se tornó irreductible cuando el PG, controlado mayoritariamente por personajes de tendencia socializante $\mathrm{O}$, al menos, preocupado por su supervivencia ligada a una República progresista y permisiva para con los nacionalismos periféricos, se involucró en las cuestiones más polémicas de la arena política española y, en ellas, se adhirió al bloque izquierdista junto con partidos que, durante el período republicano, habían mostrado en diversas ocasiones su rechazo no solo del conservadurismo sino de algunos de sus elementos como el catolicismo, siendo esta situación insostenible a ojos de los que posteriormente protagonizarían la formación de Dereita Galeguista. Primero en Pontevedra y, siguiendo su ejemplo, luego en Santiago y Ourense, algunos de los miembros más destacados del PG como Filgueira Valverde y Vicente Risco crearían diversas formaciones que, posteriormente y como consecuencia natural de las escisiones, no tardarían en configurar un solo partido que conciliase el nacionalismo gallego con la tradición y el conservadurismo profesado por sus miembros. Su distanciamiento con el PG se hizo manifiesto, sobre todo, tras el Alzamiento de 1936, que daría lugar a un régimen represivo para con el nacionalismo pero en el cual figuras como las mencionadas se hallarían más o menos cómodas e incluso llegarían a obtener grandes triunfos profesionales y artísticos. 


\section{Bibliografía}

ALFONSO BOZZO Alfonso, Los partidos políticos y la autonomía de Galicia. 1931-1936, Madrid, Akal, 1976.

ANTUÑA SOUTO Carlos, O galeguismo na provincia de Pontevedra (1930-1936), Sada, Ediciós do Castro, 2000.

BERAMENDI Justo, Vicente Risco no nacionalismo galego (2 vols.), Santiago de Compostela, Edicións do Cerne, 1981.

BERAMENDI Justo, "O nacionalismo de Otero Pedrayo", A Nosa Terra, 8 (1987), pp. 57-63.

BERAMENDI Justo, "Prensa y galleguismo en Galicia durante la II República", en Carmelo GARITAONAINDÍA y José Luis de la GRANJA (eds.), Comunicación, cultura y política durante la II República y la Guerra Civil, Bilbao, Universidad del País Vasco (tomo II), 1990, pp. 145-165.

BERAMENDI Justo, "Identidad nacional e identidad regional en España entre la Guerra del Francés y la Guerra Civil", en Los 98 Ibéricos y el Mar, III: El Estado y la Política, Madrid-Lisboa, Sociedad Estatal Lisboa '98, 1998, pp. 187-215.

BERAMENDI Justo, "As percepcións republicanas de Galicia (1868-1936)". Terra e Tempo, 9-10 (1999), pp. 9-12.

BERAMENDI Justo, "Republicanismo y nacionalismos subestatales en España (1875-1923)". Ayer, 39 (2000), pp. 135-161.

BERAMENDI Justo, "Republicanismo coruñés e galeguismo", El republicanismo coruñés en la historia, A Coruña, Concello da Coruña, 2001, pp. 185-190.

BERAMENDI Justo, De provincia a nación. Historia do galeguismo político, Vigo, Xerais, 2007.

BERAMENDI Justo y Bernardo MÁIZ (eds.), Los nacionalismos en la España de la II República, 1991.

BERAMENDI Justo y Xosé Manoel Núñez Seixas, O nacionalismo galego, Vigo, Edicións A Nosa Terra, 1995.

BOBILLO Francisco, Nacionalismo gallego. La ideología de Vicente Risco, Madrid, Akal, 1981. 
CARDEÑOSO ÁLVAREZ Severino, Nuestro amigo Ramón Otero Pedrayo, Vigo, Zero, 1979.

CASARES Carlos Vicente Risco, Vigo, Galaxia, 1981.

CASARES Carlos, Otero Pedrayo, Vigo, Galaxia, 1981.

CASTRO PÉREZ Xavier, O galeguismo na encrucillada republicana (2 vols.), Ourense, Diputación Provincial, 1985.

CORES TRASMONTE Baldomero, O Estatuto de Autonomía de Galicia (19321936). Os documentos oficiais, Santiago de Compostela, Foesga, 1998.

ESPİNO-DOMARCO Francisco, "Correspondencia Risco-Blanco Amor", Boletín Auriense, 14-15 (1986), pp. 24-57.

FERNÁNDEZ PÉREZ-SANJULIÁN Carme, A construcción nacional no discurso literario de Ramón Otero Pedrayo, Vigo, A Nosa Terra, 2003.

FERNÁNDEZ SANTANDER Carlos, El alzamiento de 1936 en Galicia, Sada, Ediciós do Castro, 1982.

FERNÁNDEZ SANTANDER Carlos, Alzamiento y Guerra Civil en Galicia (19361939) (2 vols.), Sada, Ediciós do Castro, 2000.

GARCÍA ALÉN Alfredo, "Filgueira Valverde, Xosé Fernando", en VV. AA., Gran Enciclopedia Gallega, tomo 13, Vitoria, Silverio Cañada, 1974.

GRANDÍO SEOANE Emilio, Los orígenes de la derecha gallega: la C.E.D.A. en Galicia (1931-1936), Sada, Ediciós do Castro, 1998.

GRANDÍO SEOANE Emilio (ed.), República e republicanos en Galicia, A Coruña, Ateneo Republicano de Galicia, 2006.

GRANJA José Luis, Justo BERAMENDI y Pere ANGUERA, La España de los nacionalismos y las autonomías, Madrid, Síntesis, 2001.

HERMIDA GARCÍA Modesto, As revistas literarias en Galicia na Segunda República, Sada, Ediciós do Castro, 1987.

LUGRÍS Ramón, Vicente Risco na cultura galega; Vigo, Galaxia, 1963.

MAÍZ Bernardo, Galicia na II República e baixo o franquismo, Vigo, Xerais, 1989.

RUÍZ MANJÓN Octavio, "El republicanismo centrista gallego durante la Segunda República", en Jesús de JUANA y Xavier CASTRO (eds.), VII Xornadas de Historia de Galicia, Ourense, Diputación Provincial, 1993, pp. 163-178. 
SALGADO Fernando, "El estatuto gallego del 36", Tiempo de Historia, 22 (1976), pp. 18-29.

SANTOS GAYOSO Enrique, Historia de la prensa gallega 1800-1936 (2 vols.), Sada, Ediciós do Castro, 1990-1995.

VALLE PÉREZ Xosé Carlos (ed.), Xosé Filgueira Valverde. 1906-1996. Un século en Galicia, Pontevedra, Museo de Pontevedra y Sociedad Estatal de Conmemoraciones Culturales, 2007.

VELASCO SOUTO Carlos, A Organización Republicana Gallega Autónoma (ORGA) na Segunda República e a súa incidencia no proceso autonómico galego (tesis doctoral), Santiago de Compostela, Universidad de Santiago de Compostela, 1981.

VELASCO SOUTO Carlos, Galiza na Il República, Vigo, A Nosa Terra, 2000.

VENTURA Joaquim, O nacionalismo kármico de Vicente Risco, Santiago de Compostela, Laiovento, 2000.

WOUTERS Marc (ed.), 1936. Os primeiros días, Vigo, Xerais, 1993. 